\title{
The Estimation of Direction-of-Arrivals of Wideb and Sources by Signal Subspace Focusing Approach
}

\author{
Lena Chang \\ Associated Professor, Department of Merchant Marine, National Taiwan Ocean University, Taiwan, R.O.C. \\ Chung-Fan Twu \\ Graduate Student, Department of Merchant Marine, National Taiwan Ocean University, Taiwan, R.O.C.
}

Follow this and additional works at: https://jmstt.ntou.edu.tw/journal

Part of the Engineering Commons

\section{Recommended Citation}

Chang, Lena and Twu, Chung-Fan (1998) "The Estimation of Direction-of-Arrivals of Wideb and Sources by Signal Subspace Focusing Approach," Journal of Marine Science and Technology. Vol. 6: Iss. 1, Article 2. DOI: $10.51400 / 2709-6998.2515$

Available at: https://jmstt.ntou.edu.tw/journal/vol6/iss1/2

This Research Article is brought to you for free and open access by Journal of Marine Science and Technology. It has been accepted for inclusion in Journal of Marine Science and Technology by an authorized editor of Journal of Marine Science and Technology. 


\title{
THE ESTIMATION OF DIRECTION-OF-ARRIVALS OF WIDEBAND SOURCES BY SIGNAL SUBSPACE FOCUSING APPROACH
}

\author{
Lena Chang* and Chung-Fan Twu**
}

Keywords: Signal subspace, Focusing matrix, Direction-of-arrival (DOA), Wideband.

\section{ABSTRACT}

A novel signal subspace focusing (SSF) approach for the wideband array processing is proposed in this paper. The method is based on the transformation of the signal subspaces by using focusing matrices. The focusing matrix is designed to align the signal subspaces for different frequencies in the bandwidth of the sources, and is constructed without the preliminary angle estimation. Hence, the SSF can avoid the inherent sensitivity to focusing error. Simulation results validate the effectiveness of the SSF in the estimation of the direction-of-arrivals (DOAs) of wideband sources.

\section{INTRODUCTION}

The Coherent Signal-subspace Method (CSM) [1] has been proposed for the estimation of the direction-of-arrivals (DOAs) of multiple wideband sources received by the passive array. In the CSM, the estimated spectrum density matrices of each frequency bin within the received bandwidth are first transformed onto a common frequency (usually the receiver center frequency) by focusing matrices, and then averaged to obtain a focused spectrum density matrix. Although the CSM is very effective in the wideband signal detection and estimation, it suffers from the construction of the focusing matrices which require a set of preliminary DOAs estimation by low resolution methods, such as beamforming or spectrum paradigm. If these preliminary DOAs estimation are inappropriately selected, the CSM often results in an estimation error in focusing matrices, especially in

Paper Received December, 1997. Revised March, 1998. Accepted March, 1998. Author for Correspondence: Lena Chang.

*Associated Professor, Department of Merchant Marine, National Taiwan Ocean University, Taiwan, R.O.C.

** Graduate Student, Department of Merchant Marine, National Taiwan Ocean University, Taiwan, R.O.C. multi-group signals. Thus, the estimation bias increases with the deviation of the focusing points from the true DOAs. Several focusing matrices have been suggested to construct effective focusing for the CSM. These matrices include rotation signal-subspace (RSS) [2], array manifold interpolation (AMI) [3], unitary constrained array manifold focusing (UCAM) [4] and others $[5,6]$.

In this paper, we introduce a new focusing method, named signal subspace focusing (SSF), for the DOAs estimation of wideband sources. Similar to the CSM, the SSF transforms the signal subspace, which corresponds to the spectrum density matrix, at each frequency bin onto the focusing subspace (usually the signal subspace at receiver center frequency) by using focusing matrices. The focusing matrices are unitary and are chosen to minimize the distance between the focusing subspace and the signal subspace at each frequency bin. In contrast to the CSM, in which the focusing matrices are determined by transforming the directional matrix at each frequency bin to that at focusing frequency, the focusing matrices of the SSF is formulated without the preliminary estimation of the source direction. Thus, the DOAs estimation of the proposed method is insensitive to focusing error. Simulation results validate the performance of the proposed SSF method is better than that of the CSM.

This paper is organized as follows. Section II describes the data model of wideband sources and reviews the CSM method. Section III presents the SSF method. Computer simulations are included in Section IV. Finally, Section V contains the conclusions.

\section{BACKGROUND}

This section contains a brief review on the data model and the CSM.

Data Model 
Consider a p-element arbitrary geometry array illuminated by $\mathrm{q}$ wideband sources. The source signals are band limited to a common frequency band with bandwidth B. The signal received at the $m$-th sensor can be expressed as

$$
x_{m}(t)=\sum_{i=1}^{q} a_{m i} s_{i}\left(t-\tau_{m i}\right)+n_{m}(t),
$$

where $a_{m i}$ is the complex gain of the $m$-th sensor with respect to the $i$-th source, $\tau_{m i}$ is the propagation delay for the $i$-th source at the sensor m with respect to the reference point of the array, and $n_{m}(t)$ is the additive noise at the sensor $\mathrm{m}$. For a uniform linear array $\tau_{m i}$ $=(m-1) \frac{d}{c} \sin \theta_{i}$, where $\mathrm{d}$ is the spacing between the consecutive sensors, $\mathrm{c}$ is the propagation velocity, $\theta_{i}$ is the DOA for the $i$-th source and the reference point is at the first sensor.

The received signal $x_{m}(t)$ can be represented by its Fourier components in the frequency domain. The discrete Fourier transform of $x_{m}(t)$ over the snapshot interval T consists of K Fourier components, $X_{m}\left(f_{k}\right)$, given by

$$
\begin{aligned}
X_{m}\left(f_{k}\right) & =\sum_{i=1}^{q} a_{m i} e^{-j 2 \pi f_{k} \tau} m i S_{i}\left(f_{k}\right)+N_{m}\left(f_{k}\right), \\
k & =1, \ldots K,
\end{aligned}
$$

where $S_{i}\left(f_{k}\right)$ and $N_{m}\left(f_{k}\right)$ denote the $k$-th Fourier components of the $s_{i}(t)$ and $n_{m}(t)$, respectively. The $k$-th Fourier components corresponding to the array measurements $x_{1}(t), x_{2}(t), \ldots, x_{p}(t)$ can be expressed as a vector form:

$$
\mathbf{X}\left(f_{k}\right)=\left[\begin{array}{c}
X_{1}\left(f_{k}\right) \\
X_{2}\left(f_{k}\right) \\
\vdots \\
X_{p}\left(f_{k}\right)
\end{array}\right]=\mathbf{A}\left(\theta, f_{k}\right) \mathbf{S}\left(f_{k}\right)+\mathbf{N}\left(f_{k}\right)
$$

where $\mathbf{A}\left(\theta, f_{k}\right)$ is a $p \times q$ matrix and represents the array direction matrix corresponding to frequency $f_{k}$, given by

$$
\mathbf{A}\left(\theta, f_{k}\right)=\left[\begin{array}{llll}
a\left(\theta_{1}, f_{k}\right) & a\left(\theta_{2}, f_{k}\right) & \ldots & a\left(\theta_{q}, f_{k}\right)
\end{array}\right],
$$

$\mathbf{S}\left(f_{k}\right)=\left[S_{1}\left(f_{k}\right), S_{2}\left(f_{k}\right), \ldots, S_{q}\left(f_{k}\right)\right]^{T}$ and $\mathbf{N}\left(f_{k}\right)=\left[N_{1}\left(f_{k}\right.\right.$, $\left.N_{2}\left(f_{k}\right), \ldots, N_{p}\left(f_{k}\right)\right]^{T}$ denote the vectors formed by the Fourier components of signal and noise at frequency $f_{k}$, respectively. In (4), $a\left(\theta_{i}, f_{k}\right)$ represents the direction vector of $i$-th sources at frequency $f_{k}$,

$$
a\left(\theta_{i}, f_{k}\right)=\left[\begin{array}{c}
a_{1 i} e^{-j 2 \pi f_{k} \tau_{1 i}} \\
a_{2 i} e^{-j 2 \pi f_{k} \tau_{2 i}} \\
\vdots \\
a_{p i} e^{-j 2 \pi f_{k} \tau_{p i}}
\end{array}\right], i=1,2, \ldots, q .
$$

Suppose the noise $\mathbf{N}\left(f_{k}\right)$ is independent of the source signal $\mathbf{S}\left(f_{k}\right)$ and has zero mean with known noise spectrum density matrix $P_{\eta}\left(f_{k}\right)$, but unknown spectrum level $\sigma^{2}\left(f_{k}\right)$. Hence, the spectrum density matrix of the array output is given by

$$
\begin{aligned}
P_{X}\left(f_{k}\right) & =E\left[\mathbf{X}\left(f_{k}\right) \mathbf{X}^{H}\left(f_{k}\right)\right] \\
& =\mathbf{A}\left(\theta, f_{k}\right) P_{S}\left(f_{k}\right) \mathbf{A}^{H}\left(\theta, f_{k}\right)+\sigma^{2}\left(f_{k}\right) P_{\eta}\left(f_{k}\right) .
\end{aligned}
$$

In (5), $P_{s}\left(f_{k}\right)$ is the source spectrum density matrix which may be singular in the presence of multipath propagation.

In practice, $P_{X}\left(f_{k}\right)$ is unavailable and is estimated by a sufficiently long duration of sensor output. The observation time $\mathrm{T}$ is sectioned into $\mathrm{L}$ snapshots of duration $T_{o}$ each. For sufficient large $T_{o}$, we may estimate $P_{X}\left(f_{k}\right)$ by time averaging,

$$
\hat{P}_{X}\left(f_{k}\right)=\frac{1}{L} \sum_{\ell=1}^{L} \mathbf{X}_{\ell}\left(f_{k}\right) \mathbf{X}_{\ell}^{H}\left(f_{k}\right), k=1,2, \ldots, K,
$$

where $\mathbf{X}_{\ell}\left(f_{k}\right)$ is the Fourier transform component at frequency $f_{k}$ of observations on snapshot $\ell$. The problem formulation leads to the following objective: given the data set $\mathbf{X}_{p}\left(f_{k}\right) l=1, \ldots, L, k=1, \ldots, K$, estimate the DOAs $\theta_{1}, \ldots, \theta_{q}$, of the wideband sources.

\section{Coherent Signal-subspace Method (CSM)}

The objective of the CSM is to transform the sensor output $\mathbf{X}\left(f_{k}\right)$ so that the direction matrix is constant for all frequencies within the common bandwidth of the sources. In the CSM, the observation vector $X\left(f_{k}\right)$ at different frequency bin is transformed into a new vector as

$$
\mathbf{Y}\left(f_{k}\right)=T\left(f_{k}\right) \mathbf{X}\left(f_{k}\right)
$$

where $T\left(f_{k}\right)$ is the focusing matrix and satisfies

$$
T\left(f_{k}\right) \mathbf{A}\left(\theta, f_{k}\right)=\mathbf{A}\left(\theta, f_{o}\right), \quad k=1,2, \ldots, K .
$$

In (8), $A\left(\theta, f_{o}\right)$ is the focusing direction matrix. From (5), we get the spectrum density matrix of the transformed vector $\mathbf{Y}\left(f_{k}\right)$,

$$
\begin{aligned}
P_{Y}\left(f_{k}\right) & =E\left[\mathbf{Y}\left(f_{k}\right) \mathbf{Y}^{H}\left(f_{k}\right)\right] \\
& =T\left(f_{k}\right) P_{X}\left(f_{k}\right) T^{H}\left(f_{k}\right) \\
& =\mathbf{A}\left(\theta, f_{o}\right) P_{s}\left(f_{k}\right) \mathbf{A}^{H}\left(\theta, f_{o}\right) \\
& +\sigma^{2}\left(f_{k}\right) T\left(f_{k}\right) P_{n}\left(f_{k}\right) T^{H}\left(f_{k}\right) .
\end{aligned}
$$

Equation (9) indicates the signal subspace alignment procedure which makes the transformed vectors, $\mathbf{Y}\left(f_{k}\right)$, $k=1, \ldots, K$, have the same signal subspace. Then, 
combine the spectrum density matrices $P_{Y}\left(f_{k}\right)$ over the frequency band by an averaging procedure and construct the smoothed spectrum density matrix

$$
R_{Y}=\mathbf{A}\left(\theta, f_{o}\right) R_{s} \mathbf{A}^{H}\left(\theta, f_{o}\right)+\sigma^{2} R_{\eta},
$$

where $R_{s}=\sum_{k=1}^{K} P_{S}\left(f_{k}\right), \sigma^{2}$ is the sum of noise spectral level $\sigma^{2}\left(f_{k}\right)$ across the full bandwidth and $R_{\eta}=$ $\sum_{k=1}^{K} \frac{\sigma^{2}\left(f_{k}\right)}{\sigma^{2}} T\left(f_{k}\right) P_{n}\left(f_{k}\right) T^{H}\left(f_{k}\right)$. Equation (10) indicates the estimating DOAs of the wideband sources can be performed by utilizing any super-resolution signal subspace methods proposed for estimating the DOAs of narrow-band sources, for example, the MUSIC algorithm.

Recently, several focusing matrices have been proposed to construct effective focusing for the CSM, for example the RSS [2] focusing matrices, which can be used in the CSM for estimating DOAs of wideband sources distributed in multiple clusters. In RSS, the focusing matrices are the solutions of the minimization problem

$$
\min _{T\left(f_{k}\right)}\left\|\mathbf{A}\left(\theta, f_{o}\right)-T\left(f_{k}\right) \mathbf{A}\left(\theta, f_{k}\right)\right\|_{F}, \quad k=1,2, \ldots, K,
$$

subject to

$$
T^{H}\left(f_{k}\right) T\left(f_{k}\right)=I
$$

where $\|\bullet\|_{F}$ is the Frobenius matrix norm. Minimization of (11) gives the solution of $T\left(f_{k}\right)$ as

$$
T\left(f_{k}\right)=C\left(f_{k}\right) D^{H}\left(f_{k}\right),
$$

where the columns of $C\left(f_{k}\right)$ and $D\left(f_{k}\right)$ are the left and right singular vectors of $\mathbf{A}\left(\theta, f_{k}\right) \mathbf{A}^{H}\left(\theta, f_{o}\right)$.

However, the focusing matrices in (8) and (12) require the preliminary angle estimation, which will result in the estimation bias for the CSM. To alleviate the performance degradation of the CSM, we will propose a new method for the processing of the wideband sources.

\section{SIGNAL SUBSPACE FOCUSING (SSF)}

In this section, we introduce a signal subspace focusing (SSF) method for wideband source estimation. Our method is based on the transformation of the signal subspace corresponding to the spectrum density matrix $P_{X}\left(f_{k}\right)$ into a signal subspace, named the focusing subspace. The transformation is done by using the focusing matrix, which satisfies

$$
T\left(f_{k}\right) E_{s}\left(f_{k}\right)=E_{s}\left(f_{o}\right)
$$

In (13), $E_{s}\left(f_{k}\right)=\left[e_{1}\left(f_{k}\right), e_{2}\left(f_{k}\right), \ldots, e_{q}\left(f_{k}\right)\right]$ and $E_{s}\left(f_{o}\right)=$ $\left[e_{1}\left(f_{o}\right), e_{2}\left(f_{o}\right), \ldots, e_{q}\left(f_{o}\right)\right]$, where $e_{i}\left(f_{k}\right)$ and $e_{i}\left(f_{o}\right)$, for $i=$ $1, \ldots, q$, are the eigenvectors corresponding to the $\mathrm{q}$ larger eigenvalues of $P_{X}\left(f_{k}\right)$ and $P_{X}\left(f_{o}\right)$, respectively. [2] has shown that a good focusing matrix is unitary. Hence, the focusing matrix in (13) is chosen to be unitary and satisfies the following constrained minimization problem

$$
\min _{T\left(f_{k}\right)}\left\|E_{s}\left(f_{o}\right)-T\left(f_{k}\right) E_{s}\left(f_{k}\right)\right\|_{F}, \quad k=1,2, \ldots, K,
$$

subject to

$$
T^{H}\left(f_{k}\right) T\left(f_{k}\right)=I .
$$

The solution of (14) can be get as

$$
T\left(f_{k}\right)=V\left(f_{k}\right) U^{H}\left(f_{k}\right)
$$

In (15), $V\left(f_{k}\right)$ and $U\left(f_{k}\right)$ are the matrices containing the left and right singular vectors of $E_{s}\left(f_{k}\right) E_{s}^{H}\left(f_{o}\right)$, respectively.

Using the focusing matrix in (15), the array output vector $\mathbf{X}\left(f_{k}\right)$ is transformed into a new vector,

$$
\mathbf{Y}\left(f_{k}\right)=T\left(f_{k}\right) \mathbf{X}\left(f_{k}\right), \quad k=1,2, \ldots, K .
$$

From (9) and (16), we can get the smoothed spectrum density matrix as

$$
\begin{aligned}
R_{Y} & =\sum_{k=1}^{K}\left(T\left(f_{k}\right) A\left(\theta, f_{k}\right) P_{S}\left(f_{k}\right) A^{H}\left(\theta, f_{k}\right) T^{H}\left(f_{k}\right)\right. \\
& \left.+\sigma^{2}\left(f_{k}\right) T\left(f_{k}\right) P_{n}\left(f_{k}\right) T^{H}\left(f_{k}\right)\right) .
\end{aligned}
$$

Now, we discuss the SSF method for the incoherent and coherent sources, respectively.

\section{Incoherent Sources}

For incoherent sources, we know that $\operatorname{span}\left\{e_{1}\left(f_{k}\right)\right.$, $\left.\ldots, e_{q}\left(f_{k}\right)\right]=\operatorname{span}\left(a\left(\theta_{1}, f_{k}\right), \ldots, a\left(\theta_{q}, f_{k}\right)\right\}$. Therefore, we can get the relationship

$$
E_{s}\left(f_{k}\right)=A\left(\theta, f_{k}\right) B\left(f_{k}\right) .
$$

In (18), $B\left(f_{k}\right)$ is a $q \times q$ matrix and $\operatorname{rank} B\left(f_{k}\right)=q$. The column vector $b_{i}\left(f_{k}\right)$ of matrix $B\left(f_{k}\right)$ is given by

$$
b_{i}\left(f_{k}\right)=\frac{P_{S}\left(f_{k}\right) A^{H}\left(\theta, f_{k}\right) e_{i}\left(f_{k}\right)}{\lambda_{i}\left(f_{k}\right)-\sigma^{2}\left(f_{k}\right)},
$$

where $\lambda_{1} \geq \lambda_{2} \geq \ldots \geq \lambda_{q} \geq \lambda_{q+1}=\ldots=\sigma^{2}\left(f_{k}\right)$, are the 
eigenvalues of $P_{X}\left(f_{k}\right)$ in descending order. Similarly, we get the relationship between $E_{s}\left(f_{o}\right)$ and $A\left(\theta, f_{o}\right)$ as

$$
E_{s}\left(f_{o}\right)=A\left(\theta, f_{o}\right) B\left(f_{o}\right) .
$$

Using (13), (18) and (19), the smoothed spectrum density matrix $R_{Y}$ in (17) becomes

$$
R_{Y}=A\left(\theta, f_{o}\right) R_{S} A^{H}\left(\theta, f_{o}\right)+\sigma^{2} R_{\eta},
$$

where

$$
R_{S}=\sum_{k=1}^{K} B\left(f_{o}\right) B^{-1}\left(f_{k}\right) P_{S}\left(f_{k}\right)\left(B\left(f_{o}\right) B^{-1}\left(f_{k}\right)\right)^{H},
$$

and

$$
R_{\eta}=\sum_{k=1}^{K} \frac{\sigma^{2}\left(f_{k}\right)}{\sigma^{2}} T\left(f_{k}\right) P_{\eta}\left(f_{k}\right) T^{H}\left(f_{k}\right) .
$$

Similar to the CSM, the wideband source location can be achieved by using the smoothed spectrum density matrix $R_{Y}$ in (20) with one of the several narrow-band spectrum estimation methods designed to operated at the focusing frequency $f_{o}$.

\section{Coherent Sources}

However, the above SSF is effective only for the incoherent sources. As to the coherent sources, the spatial-smoothing technique [7], proposed to decorrelated the coherence of narrow-band sources, may be applied in the SSF for the estimation of coherent wideband sources. For example, divide the array into $\mathrm{M}$ overlapped subarrays. The spatialsmoothed spectrum density matrix is formed by

$$
\bar{P}_{x}\left(f_{k}\right)=\frac{1}{M} \sum_{i=1}^{M} P_{x_{i}}\left(f_{k}\right) \text {, }
$$

where $P_{x_{i}}\left(f_{k}\right)$ is the spectrum density matrix of the ith subarray. Hence, modify the SSF with $P_{x}\left(f_{k}\right)$ replaced by $\bar{P}_{x}\left(f_{k}\right)$ for $\mathrm{M}$ coherent sources estimation.

\section{Projection Method}

Furthermore, the construction of focusing matrix $T\left(f_{k}\right)$ in (15) requires performing eigendecomposition on the spectrum density matrix $P_{X}\left(f_{k}\right)$, which will increase the computation complexity of the SSF. To reduce the computation load for the SSF, the technique of simple computation of projection matrix [8] is suggested to estimate the signal subspace. When the source number is known a priori, we can choose $\mathrm{q}$ columns (or rows) from the spectrum density matrix $P_{x}\left(f_{k}\right)$, which are $u_{i}\left(f_{k}\right), i=1, \ldots q$. In order to achieve good performance, the chosen q columns are widely spread so that they are well separated in the vector space. Those q vectors $u_{i}\left(f_{k}\right)$ are further orthogonalized by the Gram-Schmidt orthogonalization procedure and get q new vectors $u_{i}^{\prime}\left(f_{k}\right)$. Thus, the projection matrix $Q\left(f_{k}\right)$ can be formed by

$$
Q\left(f_{k}\right)=\left[u_{1}^{\prime}\left(f_{k}\right), u_{2}^{\prime}\left(f_{k}\right), \ldots, u_{q}^{\prime}\left(f_{k}\right)\right] .
$$

Yeh [8] has shown that the columns of $Q\left(f_{k}\right)$ span the same signal subspace as $P_{x}\left(f_{k}\right)$. Therefore, with the projection matrix $Q$, the minimization problem of SSF in (14) is modified as

$$
\min _{T\left(f_{k}\right)}\left\|Q\left(f_{o}\right)-T\left(f_{k}\right) Q\left(f_{k}\right)\right\|_{F}, \quad k=1,2, \ldots, K,
$$

subject to

$$
T^{H}\left(f_{k}\right) T\left(f_{k}\right)=I .
$$

By the above procedure, we can alleviate the computation burden in constructing the focusing matrix of the SSF. However, the projection method requires the apriori information on the number of sources. When source number is unknown, we can estimate the source number by information theoretic criteria, for example, by the methods based on the AIC [9] or MDL [10] criteria.

\section{SIMULATION RESULTS}

Computer simulations of both the CSM and the SSF are presented in this section. In simulations, the rotational signal-subspace (RSS) focusing matrix was used for the CSM. And the focusing angles were estimated by the delay-and-sum beamformer preliminarily for the CSM. We consider a linear array of sixteen sensors with equal spacing of half-wavelength at central frequency $100 \mathrm{~Hz}$. The source signals were band-pass zero-mean white Gaussian processes with same central frequency $100 \mathrm{~Hz}$ and band-width $40 \mathrm{~Hz}$. 100 snapshots were used, and for each snapshot, 33 frequency components of array output were obtained via DFT.

The simulation was first performed for the case of uncorrelated sources in multi-group scenario. The sources were distributed at $10^{\circ}, 13^{\circ}, 30^{\circ}$ and $37^{\circ}$ with equipower $\mathrm{SNR}=10 \mathrm{~dB}$. Fig. 1 shows that the $\mathrm{SSF}$ is much effective in the estimation of DOAs of wideband sources in multi-group scenario. Next, we considered the case of multiple arrivals falling in one group. Four uncorrelated sources were located $9^{\circ}, 12.5^{\circ}, 16^{\circ}$ and $35^{\circ}$, and the first three sources belongs to one group. Fig. 2 shows the resolution property of the SSF is better than the CSM for the case of multiple arrivals 


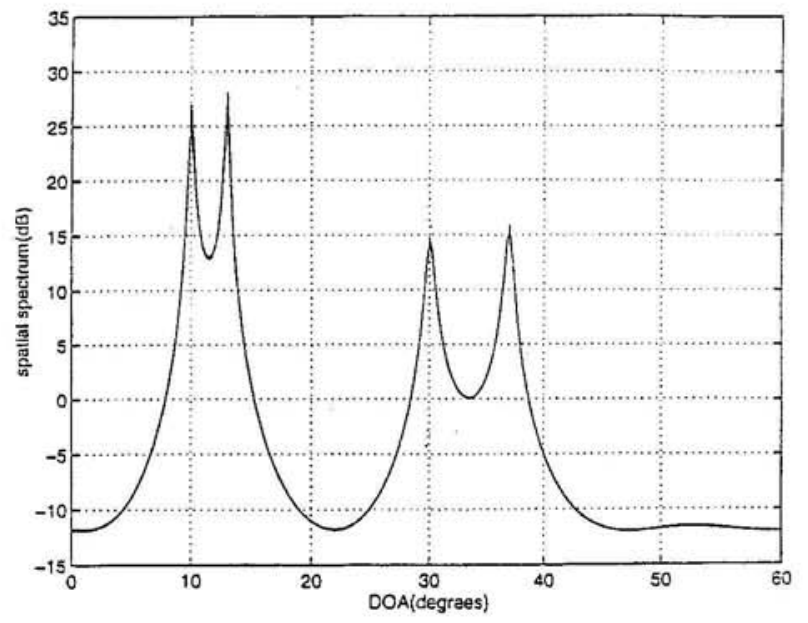

(a) $\mathrm{CSM}$

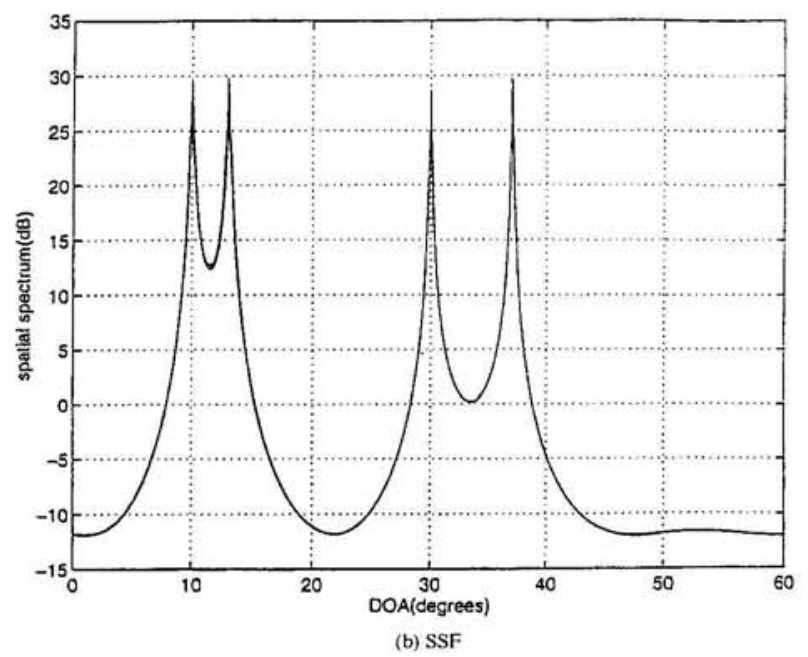

Fig. 1. Spatial spectrum for multi-group signals (a) CSM, (b) SSF. A sixteen-element spaced linear array with half-wavelength spacing illuminated by four signals located at $10^{\circ}, 13^{\circ}, 30^{\circ}$ and $37^{\circ}$ with $\mathrm{SNR}=10 \mathrm{~dB}$.

within one group. Then, the statistics analysis for the SSF was estimated by 100 independent Monte Carlo trials. Four uncorrelated sources with $\mathrm{SNR}=10 \mathrm{~dB}$ were located at $10^{\circ}, 15^{\circ}, 30^{\circ}$ and $35^{\circ}$. The bias, standard deviation (std) and mean square error (MSE) were listed in Table 1 at various SNRs. In the table, $\mathrm{CSM}^{(1)}$ indicated the CSM with good focusing angles $12.5^{\circ}$ and $32.5^{\circ}$, and $\operatorname{CSM}^{(2)}$ represented the CSM with focusing angles estimated by the delay-and-sum beamformer. Table 1 shows that $\mathrm{CSM}^{(1)}$ has lower bias and standard deviation than $\mathrm{CSM}^{(2)}$, which indicates the sensitivity problem of the CSM. Also, we can observe that the performance of the SSF becomes better as the SNR increases. The result is reasonable since the estimation of signal subspace is more accurate for larger SNR. However, the bias of the SSF shown in Table 1 is still lower than that of the CSM.

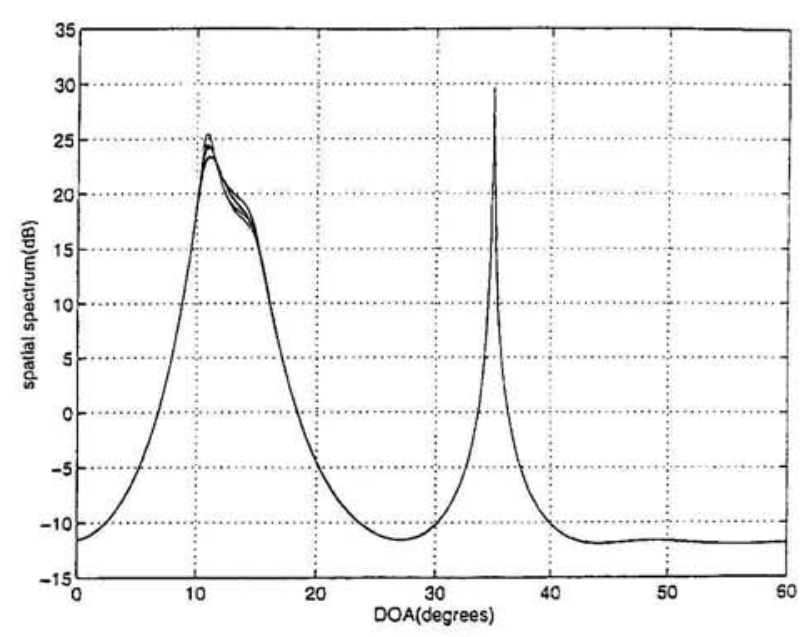

(a) CSM

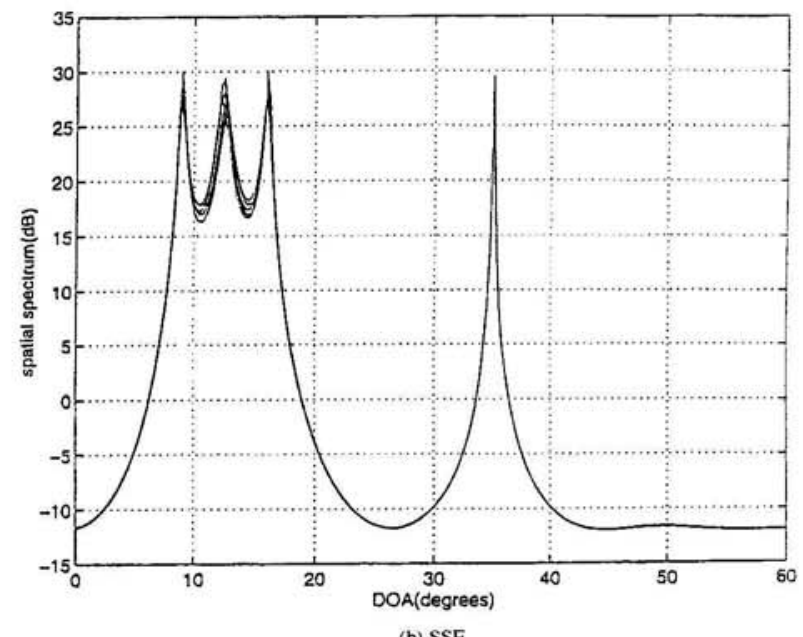

(b) SSF

Fig. 2. Spatial spectrum for multiple sources within one group. (a) CSM, (b) SSF. Simulation scenario as Fig. 1. Four signals located at $9^{\circ}, 12.5^{\circ}, 16^{\circ}$ and $35^{\circ}$ with $\mathrm{SNR}=10 \mathrm{~dB}$. Five independent simulation trials.

Finally, the simulation was carried out for coherent sources. In the simulation, the array was divided into 2 subarrays with 15 element sensors each. Four sources were located at $-50^{\circ},-10^{\circ}, 20^{\circ}$ and $25^{\circ}$ and the last two signals $s_{3}(t)$ and $s_{4}(t)$ were coherent with $s_{4}(t)=s_{3}(\mathrm{t}-0.125 \mathrm{~s})$. Fig. 3 validates the performance of SSF for coherent sources.

\section{CONCLUSIONS}

In this paper, we have proposed a new SSF method for the DOA estimation of wideband sources. The SSF transforms the signal subspace at each frequency bin onto the focusing subspace by using focusing matrices. The focusing matrix is formed without a priori knowledge of source angles. Thus, the SSF avoids the sensitivity problem caused by 
Table 1. Statistical analysis for CSM and SSF. Four signals located at $10^{\circ}, 15^{\circ}, 30^{\circ}$ and $35^{\circ}$ and $\mathrm{SNR}=10 \mathrm{~dB}$.

\begin{tabular}{|c|c|c|c|c|c|c|c|c|c|}
\hline \multirow{2}{*}{$\begin{array}{l}\theta=10^{\circ} \\
\text { SNR }\end{array}$} & \multicolumn{3}{|c|}{$\operatorname{CSM}^{(1)}$} & \multicolumn{3}{|c|}{$\mathrm{CMS}^{(2)}$} & \multicolumn{3}{|c|}{ SSF } \\
\hline & Bias & std. & MSE. $\left(\times 10^{-2}\right)$ & Bias & std. & MSE. $\left(\times 10^{-2}\right)$ & Bias & std. & MSE. $\left(\times 10^{-2}\right)$ \\
\hline $0 \mathrm{~dB}$ & 0.0260 & 0.0101 & 0.0784 & 0.1252 & 0.1669 & 4.3528 & 0.0228 & 0.0855 & 0.7833 \\
\hline $5 \mathrm{~dB}$ & 0.0265 & 0.0069 & 0.0748 & 0.1117 & 0.1387 & 3.1708 & 0.0032 & 0.0517 & 0.2682 \\
\hline $10 \mathrm{~dB}$ & 0.0269 & 0.0047 & 0.0747 & 0.0799 & 0.0731 & 1.1716 & 0.0018 & 0.0271 & 0.0737 \\
\hline $15 \mathrm{~dB}$ & 0.0273 & 0.0040 & 0.0761 & 0.0997 & 0.0773 & 1.5910 & 0.0005 & 0.0167 & 0.0280 \\
\hline $20 \mathrm{~dB}$ & 0.0266 & 0.0047 & 0.0732 & 0.1079 & 0.1310 & 2.8808 & 0.0011 & 0.0088 & 0.0079 \\
\hline$\theta=15^{\circ}$ & \multicolumn{3}{|c|}{$\operatorname{CSM}^{(1)}$} & \multicolumn{3}{|c|}{$\mathrm{CMS}^{(2)}$} & \multicolumn{3}{|c|}{ SSF } \\
\hline SNR & Bias & std. & MSE. $\left(\times 10^{-2}\right)$ & Bias & std. & MSE. $\left(\times 10^{-2}\right)$ & Bias & std. & MSE. $\left(\times 10^{-2}\right)$ \\
\hline $0 \mathrm{~dB}$ & -0.0455 & 0.0088 & 0.2146 & -0.0719 & 0.1163 & 1.8702 & 0.0230 & 0.0925 & 0.9091 \\
\hline $5 \mathrm{~dB}$ & -0.0445 & 0.0060 & 0.2013 & -0.0627 & 0.1245 & 1.9428 & -0.0094 & 0.0528 & 0.2876 \\
\hline $10 \mathrm{~dB}$ & -0.0438 & 0.0041 & 0.1931 & -0.0583 & 0.0972 & 1.2840 & 0.0024 & 0.0300 & 0.0905 \\
\hline $15 \mathrm{~dB}$ & -0.0435 & 0.0039 & 0.1904 & -0.0684 & 0.1183 & 1.8687 & -0.0002 & 0.0170 & 0.0291 \\
\hline $20 \mathrm{~dB}$ & -0.0434 & 0.0037 & 0.1898 & -0.0759 & 0.1095 & 1.7744 & -0.0019 & 0.0084 & 0.0073 \\
\hline$\theta=30^{\circ}$ & \multicolumn{3}{|c|}{$\operatorname{CSM}^{(1)}$} & \multicolumn{3}{|c|}{$\mathrm{CMS}^{(2)}$} & \multicolumn{3}{|c|}{ SSF } \\
\hline SNR & Bias & std. & MSE. $\left(\times 10^{-2}\right)$ & Bias & std. & MSE. $\left(\times 10^{-2}\right)$ & Bias & std. & MSE. $\left(\times 10^{-2}\right)$ \\
\hline $0 \mathrm{~dB}$ & 0.0504 & 0.0113 & 0.2663 & 0.1518 & 0.1648 & 5.0190 & -0.0013 & 0.0571 & 0.3266 \\
\hline $5 \mathrm{~dB}$ & 0.0498 & 0.0071 & 0.2535 & 0.1086 & 0.1225 & 2.6806 & -0.0058 & 0.0333 & 0.1141 \\
\hline $10 \mathrm{~dB}$ & 0.0485 & 0.0052 & 0.2376 & 0.1418 & 0.1374 & 3.8986 & 0.0016 & 0.0175 & 0.0308 \\
\hline $15 \mathrm{~dB}$ & 0.0480 & 0.0047 & 0.2330 & 0.1673 & 0.2137 & 7.3660 & 0.0014 & 0.0119 & 0.0144 \\
\hline $20 \mathrm{~dB}$ & 0.0487 & 0.0045 & 0.2395 & 0.1229 & 0.1198 & 2.9464 & 0.0004 & 0.0065 & 0.0042 \\
\hline$\theta=35^{\circ}$ & \multicolumn{3}{|c|}{$\operatorname{CSM}^{(1)}$} & \multicolumn{3}{|c|}{$\mathrm{CMS}^{(2)}$} & \multicolumn{3}{|c|}{ SSF } \\
\hline SNR & Bias & std. & MSE. $\left(\times 10^{-2}\right)$ & Bias & std. & MSE. $\left(\times 10^{-2}\right)$ & Bias & std. & MSE. $\left(\times 10^{-2}\right)$ \\
\hline $0 \mathrm{~dB}$ & -0.0284 & 0.0137 & 0.0996 & -0.2039 & 0.2456 & 10.1889 & 0.0125 & 0.0647 & 0.4340 \\
\hline $5 \mathrm{~dB}$ & -0.0320 & 0.0089 & 0.1104 & -0.1744 & 0.2197 & 7.8690 & 0.0041 & 0.0368 & 0.1370 \\
\hline $10 \mathrm{~dB}$ & -0.0301 & 0.0050 & 0.0930 & -0.1628 & 0.2138 & 7.2206 & -0.0058 & 0.0219 & 0.0515 \\
\hline $15 \mathrm{~dB}$ & -0.0298 & 0.0053 & 0.0916 & -0.1926 & 0.2138 & 8.2788 & 0.0004 & 0.0105 & 0.0110 \\
\hline $20 \mathrm{~dB}$ & -0.0300 & 0.0049 & 0.0923 & -0.2047 & 0.2473 & 10.3070 & -0.0001 & 0.0071 & 0.0051 \\
\hline
\end{tabular}

$\operatorname{CSM}^{(1)}$ : the CSM with focusing angles $12.5^{\circ}$ and $32.5^{\circ} ; \mathrm{CSM}^{(2)}$ : the CSM with focusing angles estimated by delay-and-sum beamformer
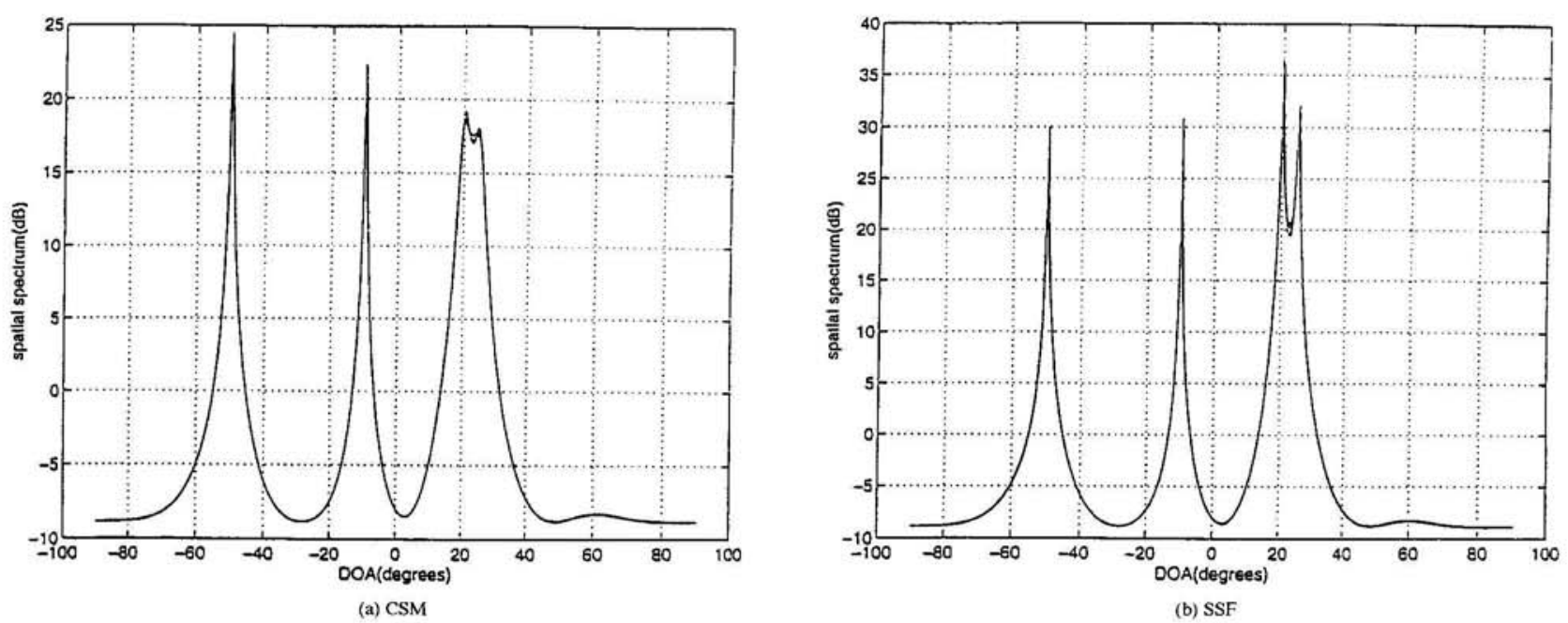

Fig. 3. Spatial spectrum for coherent signals (a) CSM, (b) SSF. Simulation scenario as Fig. 1. Four signals located at $-5^{\circ},-10^{\circ}, 20^{\circ}$ and $25^{\circ}$ with SNR=10dB. $s_{3}(t)$ and $s_{4}(t)$ are coherent, where $s_{4}(t)=s_{3}(t-0.125 s)$. 
preliminary angle estimate. Simulations indicate the SSF is much effective in the wideband source estimation than the CSM, especially for the case of multigroup signals. And the resolution and the statistics performance of the SSF are better than those of the CSM.

\section{REFERENCES}

1. Wang, and Kaveh, M., "Coherent Signal-Subspace Processing for the Direction and Estimation of Angles of Arrival of Multiple Wide-Band Sources," IEEE Trans. Acoustics, Speech, Signal Process., Vol. 33, pp. 823-831, Aug. (1985).

2. Hung, H. and Kaveh, M., "Focusing Mmatrices for Coherent Signal-Subspace Processing," IEEE Trans. Acoustics, Speech, Signal Process., Vol. 36, pp. 12721281, Aug. (1988).

3. Doron, M.A., Doron, E. and Weiss, A.J., "Coherent Wide-Band Processing for Arbitrary Array Geometry," IEEE Trans. Signal Process., Vol. 41, pp. 414417, Jan. (1993).

4. Hung, H. and Mao, C., "Robust Coherent SignalSubspace Processing for Direction-of-Arrival Estimation of Wide-Band Sources," IEE Proc. Radar, Sonar Navig., Vol. 141, No. 5, pp. 256-262, Oct. (1994).

5. Tsai, C.J. and Yang, J.F., "Auto-Focusing Technique for Adaptive Coherent Signal-Subspace Transformation Beamformers," IEE Proc. Radar, Sonar Navig. Vol. 141, No. 5, Oct. (1994).

6. Krolick, J. and Swingler, D., "Focused Wide-Band Array Processing by Spatial Resampling," IEEE Trans. Acoustics, Speech, Signal Process., Vol. 38, pp. 356360, Feb. (1990).
7. Shan, T.J., Wax, M. and Kailath, T., "On Spatial Smoothing for Direction-of-Arrival Estimation of Coherent Signals," IEEE Trans. Acoustics, Speech, Signal Process., Vol. 33, No. 4, pp. 806-811, Aug. (1985).

8. Yeh, C.C., "Simple Computation of Projection Matrix for Bearing Estimations," IEE Proc., Vol. 134, Pt. F, pp. 146-150, Apr. (1987).

9. Akaike, H., "Information Theory and an Extension of the Maximum Likelihood Principle," Proc. 2nd Int. Symp. Inform. Theory, pp. 267-281 (1973).

10. Rissanen, J., "Modeling by the Shortest Data Description," Automatica, Vol. 14, pp. 465-471 (1978).

\section{以信號子空間聚焦法進行寬頻訊號 源方位估測}

\section{張 麗 娜 涂 鐘 籁}

國立台殍海洋大學商船學系

$$
\text { 摘 要 }
$$

本論文提出一高解析度之信號子空間聚焦法 進行寬頻同調訊號源之方位估测。此法乃利用一聚 焦矩陣將不同頻率所對應之信號子空間䡜換到中心 (或聚焦) 頻率上, 形成一聚焦子空間, 而後將高 解析度之窄頻方位估测法用於此聚焦頻率上。此聚 焦矩陣之形成不需預估方位, 故信號子空間聚焦法 可減緩因聚焦誤差所造成之估测偏差。電腦模擬驗 證信號子空間聚焦法可有效估测寬頻同調訊號源之 方位。 